Original Research Paper

\title{
Pemanfaatan Limbah Plastik Sebagai Media Tanam Dengan Metode Vertikultur Hidroponik Untuk Memaksimalkan Fungsi Pekarangan Di Desa Pringgabaya
}

\author{
Satrijo Saloko ${ }^{*}$, Muhammad Nursan ${ }^{2}$, Rizka Amalia $^{3}$, Sopiandi $^{4}$ \\ ${ }^{1}$ Program Studi Ilmu dan Teknologi Pangan, Universitas Mataram, Indonesia \\ ${ }^{2}$ Program Studi Agribisnis, Universitas Mataram, Indonesia \\ ${ }^{3}$ Program Studi Farmasi, Universitas Mataram, Indonesia \\ ${ }^{4}$ Program Studi Perairan, Universitas Mataram, Indonesia
}

https://doi.org/10.29303/jpmpi.v3i2.995

Sitasi: Saloko, S., Nursan, M., Amalia, R \& Sopiandi. (2021). Pemanfaatan Limbah Plastik Sebagai Media Tanam Dengan Metode Vertikultur Hidroponik Untuk Memaksimalkan Fungsi Pekarangan Di Desa Pringgabaya . Jurnal Pengabdian Magister Pendidikan IPA, 4(4)

Article history

Received: 15 September 2021

Revised: 20 September 2021

Accepted: 25 September 2021

*Corresponding Author:

Satrijo Saloko, Program

Studi Ilmu dan Teknologi

Pangan, Universitas

Mataram, Indonesia;

Email: s_saloko@unram.ac.id

\begin{abstract}
Sustainable Food House is a program to optimize the use of environmentally friendly yards, and is designed to help meet family quality and nutritional needs, food diversification based on local resources, plant conservation, and increasing household income through non-rice based household creative industries for local food processing. . The objectives of this community service program (1) increase knowledge and skills, awareness and motivate the people of Pringgabaya Village, especially the group of housewives in the use of vacant land or yards, (2) apply some simple techniques for planting yards and their maintenance that can be implemented effectively. easy for the people. The types of plants that are planted in the yard are types of vegetables that can support daily needs and the rest can be sold. Methods of activities carried out include socialization, training, and practice starting from land preparation, maintenance, development, implementation and demonstration. This activity is able to encourage and increase the awareness of the group of housewives in utilizing the yard, especially using the verticulture method of hydroponics, starting from seedling to plant maintenance.
\end{abstract}

Keywords: Community Service; Sustainable Food House; Vertikultur Hidroponik Method; Yard Land.

\section{Pendahuluan}

Peningkatan pertumbuhan penduduk pada setiap daerah tidak dapat terelakkan sehingga lahan yang produktif untuk kegiatan pertanian dan budidaya berubah fungsi menjadi pemukiman yang padat akan penduduk. Kondisi ini menyebabkan lahan menjadi semakin sempit dan berkurang sehingga terjadi keterbatasan lahan untuk kegiatan pertanian. Hal ini pula terkadang yang menyebabkan banyak dari para petani berubah profesi ke bidang lain guna memenuhi kebutuhan ekonominya. Keadaan ini cepat atau lambat dapat menyebabkan penurunan hasil pertanian khususnya pangan di suatu daerah. Berkurangnya produksi pangan akan berakibat pada pemenuhan kebutuhan pangan masyarakat. Hal ini sejalan dengan pendapat Sasongko et al., (2017) produksi pangan akan berkurang dengan adanya konversi lahan pertanian ke lahan pemukiman.

Program Kawasan Rumah Pangan Lestari (KRPL) merupakan program yang dibentuk oleh kementerian pertanian pada tahun 2011 dengan 
tujuan untuk memenuhi ketersediaan pangan dan gizi keluarga, mengembangkan sumber pembibitan dan pelestarian pangan lokal, serta menumbuh kembangkan ekonomi kreatif keluarga (Badan Litbang Pertanian RI, 2017). Prinsip dasar KRPL adalah pemanfaatan pekarangan yang ramah lingkungan dan dirancang untuk pemenuhan kebutuhan pangan keluarga untuk mendukung ketahanan pangan nasional dengan memberdayakan potensi pangan lokal yang dimiliki masing-masing daerah.

Salah satu cara yang dapat dilakukan untuk memanfaatkan lahan pekarangan yang ada sebagai tempat budidaya tanaman adalah dengan menggunakan metode vertikultur berbasis hidroponik. Hidayati et al., (2018) menyatakan bahwa lahan pekarangan dapat digunakan untuk budidaya tanaman dengan menggunakan metode vertikultur karena tidak membutuhkan lahan yang luas sehingga kegiatan budidaya dapat dilakukan dengan efisien. Selain itu, menurut Romadhona et al., (2019), metode vertikultur ini juga sangat baik dijadikan sebagai inovasi dan teknologi budidaya di lahan pekarangan, karena memiliki beberapa kelebihan seperti penggunaan lahan yang efisien, hemat penggunaan pupuk dan pestisida, tanaman mudah dipindahkan, dan tanaman mudah dipelihara.

Metode hidroponik vertikultur merupakan sistem bercocok tanam secara hidroponik dan dilakukan secara vertikal. Dimana tanaman yang dibudidayakan disusun dalam model bertingkat dari bawah ke atas dengan tujuan memanfaatkan lahan yang luasnya terbatas atau sempit agar lebih optimal (Surtinah \& Nurwati, 2018; Yosandy et al., 2018). Beberapa tanaman yang dapat dibudidayakan dengan menggunakan metode hidroponik vertikultur diantaranya yaitu jenis tanaman hias, sayuran, dan buah-buahan (Sitawati et al., 2016; Romadhona et al., 2019).

Teknik hidroponik vertikultur dapat diterapkan dengan cara menggunakan beberapa macam tempat atau wadah bekas seperti botol plastik bekas, rak plastik bekas, dan lain-lain (Gaidajis et al., 2010; Karya et al., 2015). Selain itu, budidaya tanaman pada kegiatan ini juga dilakukan dengan budidamber. Budidamber tidak membutuhkan lahan yag banyak karena media utamanya menggunakan ember, dan tidak membutuhkan volume air yang banyak.

Desa Pringgabaya merupakan salah satu desa dari 15 (lima belas) Desa yang ada di wilayah
Kecamatan Pringgabaya, Kabupaten Lombok Timur, Provinsi Nusa Tenggara Barat (NTB), dengan letak geografis berada pada koordinat $117^{\circ}$ Bujur Timur dan $8^{\circ}$ Lintang Selatan dan memiliki luas wilayah sebesar $2.309 \mathrm{Ha} / \mathrm{m}^{2}$. Populasi penduduk di Desa Pringgabaya mencapai \pm 15.414 jiwa dengan jumlah kepala keluarga sebesar \pm 5.513 dan setiap tahunnnya mengalami peningkatan sehingga kebutuhan pangan juga semakin bertambah. Dalam rangka memenuhi kebutuhan pangan keluarga, salah satu upaya yang dapat dilakukan oleh masyarakat di Desa Pringgabaya adalah dengan memanfaatkan lahan pekarangan untuk melakukan budidaya tanaman dengan menggunakan metode hidroponik vertikultur. Oleh karena itu, tujuan dari program pengabdian masyarakat ini (1) meningkatkan pengetahuan dan ketrampilan, kesadaran serta memotivasi masyarakat Desa Pringgabaya khususnya kelompok ibu-ibu rumah tangga dalam pemanfaatan lahan kosong atau pekarangan, (2) menerapkan teknik hidroponik vertikultur untuk penanaman lahan pekarangan dan pemeliharaannya yang dapat diimplementasikan secara mudah oleh masyarakat.

\section{Metode}

Pelaksanan kegiatan pemanfaatan limbah plastik sebagai media tanam dengan metode vertikultur hidroponik ini dilakukan dengan menggunakan metode sosialisasi, pelatihan dan praktek langsung di lahan pekarangan masyarakat di Desa Pringgabaya. Kegiatan sosialisasi dilakukan kepada kelompok mitra yaitu kelompok ibu rumah tangga yang ada di desa Desa Pringgabaya. Adapun beberapa tahapan kegiatan yang dilakukan meliputi.

\section{Persiapan}

Pada tahap ini, dilakukan pertemuan dengan kepala desa atau staf desa untuk mencari informasi terkait potensi dan profil masyarakat yang ada di desa Pringgabaya.

2. Perencanaan kegiatan

Pada tahap ini, dilakukan perencanaan atau merancang bagaimana pemanfaatan lahan pekarangan dengan pemanfaatan limbah plastik untuk menanam berbagai tanaman pangan berupa sayuran dengan metode vertikultur hidroponik dan budidamber. Alat yang digunakan pada kegiatan ini berupa bekas bungkus minyak sebagai media tanam, ember bekas sebagai media budidamber, botol plastic 
bekas, gergaji, palu, paku, tang, kawat, silet, trai telur. Bahan yang digunakan pada kegiatan ini adalah bambu, benih (selada, tering, cabe, bawang merah, sawi, pakcoy, seledri, kangkung, kunyit, jahe, dan lele), kain flannel, nutrisi tanaman, Paranet, tanah dan air sebagai bahan media tanam.

3. Melakukan pembibitan

Dalam melakukan pembibitan kami memanfaatkan terai telur sebagai media tanam. Pembibitan dilakukan sampai benih tersebut berkecambah.

4. Melakukan pindah tanam

Jika bibit sudah berkecambah maka dilakukan pindah tanam ke media tanam yang sudah diperseiapkan.

5. Melakukan perawatan

Dalam proses perawatan meliputi; penyiangan yaitu proses pembersihan gulmagulma yang berada disekitar tanaman. Kemudian penyiraman, dimana proses pemberian air pada tanaman. Lalu pemberian nutrisi berupa unsur-unsur hara dasar seperti N,P dan K.

\section{Sosialisasi}

Kegiatan sosialisasi dilakukan untuk menyampaikan maksud dan tujuan kegiatan serta pengenalan program rumah pangan lestari dengan metode vertikultur hidroponik dan budidamber yang akan dilaksanakan. Kegiatan sosialisasi dilakukan kepada kelompok Ibu Rumah Tangga di Desa Pringgabaya. Kegiatan sosialisasi ini meliputi pelatihan dan praktek di lapangan. Jenis pelatihan yang dilakukan yaitu bagaimana cara mengolah sampah plastik untuk membudidayakan tanaman pangan sayuran, mulai dari pembenihan dan pembibitan dengan teknik vertikultur hidroponik dan budidamber. Serta cara untuk merawat tanaman yang dibudidayakan.

\section{Hasil dan Pembahasan}

Kegiatan ini dilaksanakan untuk mecapai tujuan yang telah di tetapkan. Kegiatan Rumah Pangan Lestari dilaksankan di pekarangan desa berukuran $10 \times 8 \mathrm{~m}$ dengan menanam sayur berupa sawi, seledri, pak coy, terong, kangkung, cabe, kunyit, jahe, tanaman obat. Menurut Putri et al., (2015), kegiatan Rumah Pangan Lestari termasuk salah satu upaya bersama untuk meningkatkan ketahanan pangan dan gizi keluarga.

Realiasi yang dilakukan pertamakali adalah melakukan pembibitan. Pembibitan dilakukan menggunakan terai telur berukuran 10 x 10 untuk masing masing bibit.

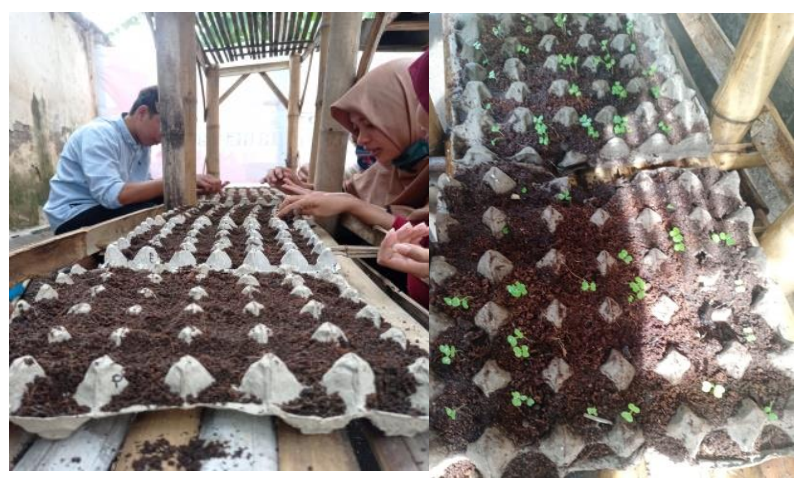

Gambar 1. Kegiatan Pembibitan

Setelah dilakukan pembibitan dan bibit dirasa sudah cukup untuk pindah tanam, maka dilakukan pindah tanam dengan metode vertikikultur hidroponik. Penggunaan metode ini akan memudahkan pemindahan tanaman (Romadhona et al., 2019). Hasil dari pindah tanam ini diperoleh tanaman yang tumbuh subur dan diharapkan dapat dilakukan pemanenan.

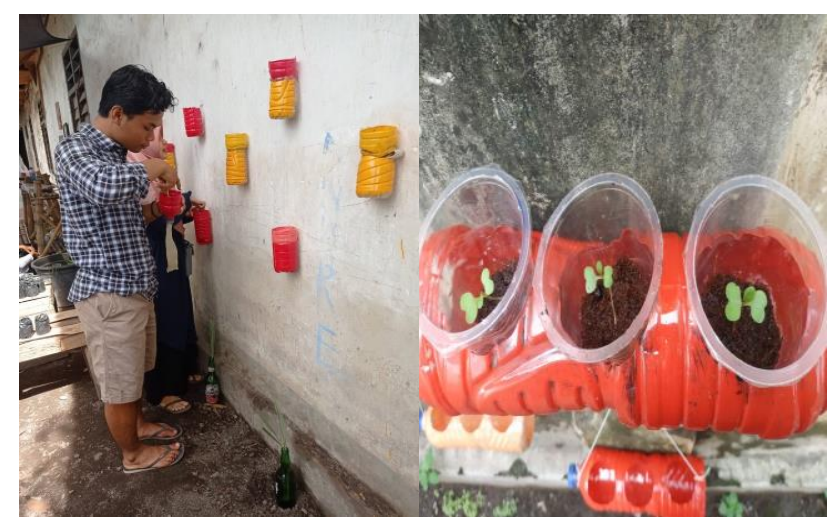

Gambar 2. Kegiatan Pimindahan Tanaman metode vertikikultur hidroponik

Perawatan tanaman ini dilakukan untuk memberikan nutrisi pada tanaman supaya tanaman dapat tumbuh subur dan tetap dalam keadaan yang diharapkan. Perawatan ini dilakukan dengan pemberian nutrisi $\mathrm{AB}$ mix yang diberikan secara berkala yaitu sebanyak 2 kali dalam satu minggu. Selain itu, kontrol tanaman juga tetap dilakukan 
untuk memastikan tanaman tetap dalam pengawasan dan menghasilkan tanaman sayur yang sehat untuk dikonsumsi masyarakat. Hasil dari perawatan tanaman ini didapatkan tanaman cukup tumbuh subur yang dibuktikan dengan tinggi dari tanaman tersebut yaitu rata-rata mencapai $10-15$ $\mathrm{cm}$.

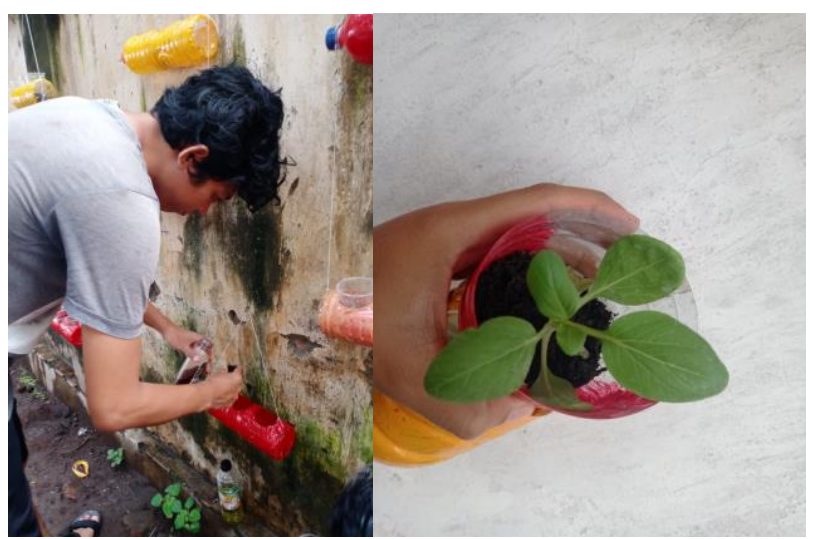

Gambar 3. Kegiatan Perawatan Tanaman

Sosialisasi dilakukan kepada masyarakat untuk menyampaikan maksud dan tujuan dari pengembangan Rumah Pangan Lestari (RPL) yang diprogramkan. Kegiatan ini juga dilakukan untuk memperkenalkan kepada masyarakat terkait metode RPL berbasis hidroponik dan budidamber sehingga diharapkan dapat dipraktekkan di halaman rumahnya masing-masing. Pelaksanaan kegiatan secara keseluruhan berjalan dengan baik dan mendapatkan respon yang baik dari masyarakat. Masyarakat menjadi paham dan termotivasi untuk melakukan kegiatan pemanfaatan lahan pekarangan dengan penanaman mengunakan metode vertikultur.

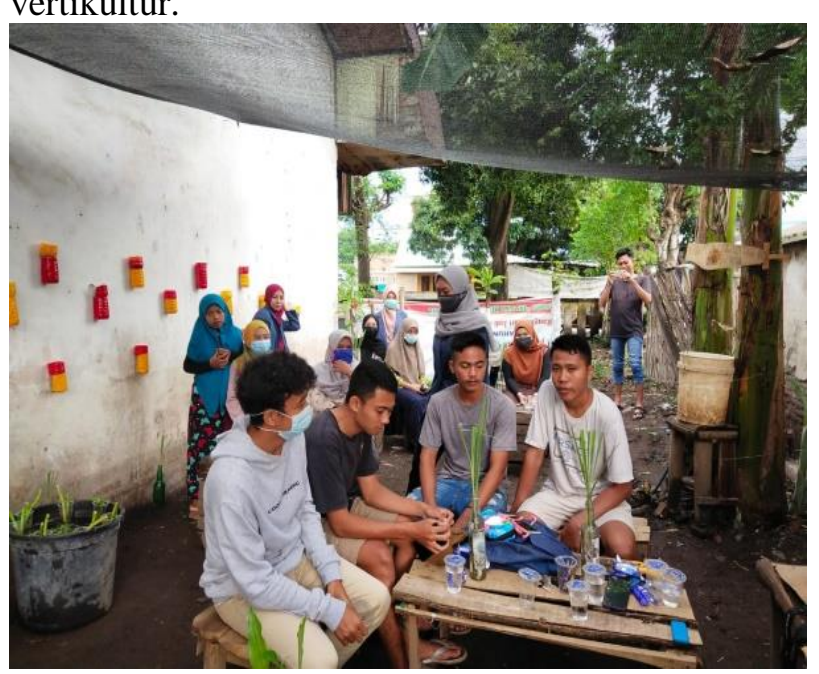

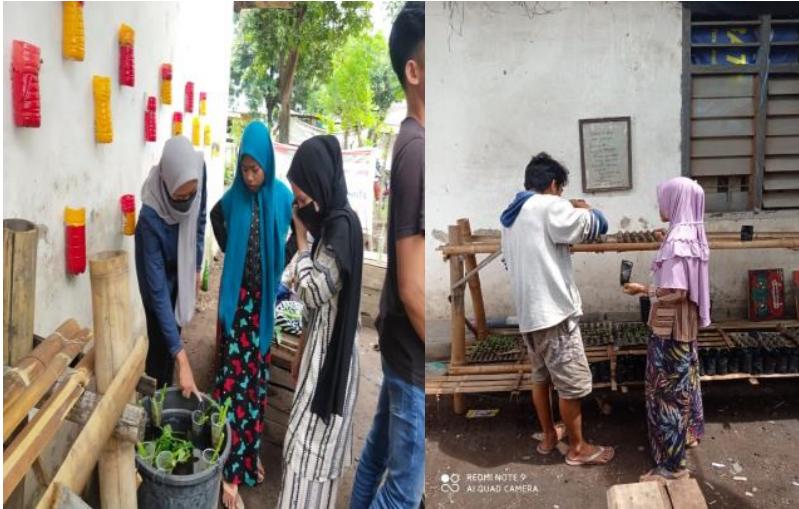

Gambar 4. Kegiatan Sosialisasi Kepada Masyarakat

\section{Kesimpulan}

Kegiatan pengabdian terkait pemanfaatan lahan pekarangan untuk melakukan budidaya tanaman dengan menggunakan metode vertikultur hidroponik dilakukan dengan memberikan sosialisasi, pelatihan dan praktek langsung kepada kelompok masyarakat yang ada di Desa Pringgaya. Jenis-jenis tanaman yang ditanam di lahan pekarangan dengan metode vertikultur hidroponik adalah jenis sayur-sayuran yang dapat menunjang kebutuhan sehari-hari dan selebihnya bisa dijual. Kegiatan ini mampu mendorong dan meningkatkan kesadaran kelompok ibu rumah tangga dalam memanfaatkan lahan pekarangan khususnya menggunakan metode vertikultur hidroponik mulai pembibitan sampai pemeliharaan tanaman.

\section{Saran}

Dengan adaya kegiatan ini diharapkan masyarakat setempat dapat melakukan kegiatan tersebut guna memanfaatkan lahan pekarangan untuk ketahanan pangan dan menunjang kebutuhan ekonomi masyarakat di Desa Pringgabaya.

\section{Daftar Pustaka}

Badan Litbang Pertanian RI. (2017). Kawasan Rumah Pangan Lestari Jakarta. Kementerian Pertanian Republik Indonesia.

Gaidajis, G., Angelakoglou, K., \& Aktsoglou, D. (2010). E-waste: Environmental problems and current management. Journal of Engineering 
Science and Technology Review, 3(1), 193199. https://doi.org/10.25103/jestr.031.32

Hidayati, N., Piueyani, R., Fahrudin, A., \& Nanang, H. (2018). Pemanfaatan Lahan Sempit Untuk Budidaya Sayuran Dengan Sistem Vertikultur. Jurnal Umpalangkaraya, 3(1), 40-46.

Karya, B., Hawalid, H., \& Hawayanti, E. (2015). Pengaruh jenis rakit limbah botol plastik dan jenis pupuk organic padat terhadap pertumbuhan dan produksi tanaman sawi (Brassica oleracea L. Var. alboglabra Bailey) di lahan rawa lebak yang tergenang. Klorofil, 10(2), 106-110.

Putri, N. P. A., Aini, N., \& Heddy, Y. B. S. (2015). Evaluasi Keberlanjutan Kawasan Rumah Pangan Lestari (KRPL) di Desa Girimoyo, Kecamatan KArangploso. Jurnal Produksi Tanaman, 3(4), 1-4.

Romadhona, S., Sudibya, J., Sutikto, T., Mutmainnah, L., \& Rambi, A. (2019). Pemanfaatan Limbah Gelas dan Botol Plastik Sebagai Media Tanam Penunjang Peningkatan Pendapatan Masyarakat Melalui Pembentukan Kampung Hidroponik di Lahan Rawa. Warta Pengabdian, 13(4), 147-156. https://doi.org/10.19184/wrtp.v13i4.11314

Sasongko, W., Safari, I., \& Sari, K. (2017). Konversi Lahan Pertanian Produktif Akibat Pertumbuhan Lahan Terbangun Di Kecamatan Kota Sumenep. Plano Madani: Jurnal Perencanaan Wilayah Dan Kota, 6(1), 15-26. https://doi.org/10.24252/planomadani.6.1.1526

Sitawati, S., Suryanto, A., \& Elih Nurlaelih, E. (2016). Optimization of Plant Growth and Yield Through Innovation of The Materials and Medium Verticulture. Research Journal of Life Science, 3(3), 55-64. https://doi.org/10.21776/ub.rjls.2016.003.01.8

Surtinah, \& Nurwati, N. (2018). Optimalisasi pekarangan sempit dengan tanaman sayuran pada kelompok ibu rumah tangga. Jurnal Pengabdian Dan Pemberdayaan Masyarakat, 2(2), 193-199.

Yosandy, D. S. O., Baskara, M., \& Herlina, N. (2018). Pengaruh media tanam pada sistem vertikultur terhadap pertumbuhan dan hasil tanaman. Jurnal Produksi Tanaman, 6(2), 210-216. 